Available online on 15.12.2019 at http://jddtonline.info
Open Access to Pharmaceutical and Medical Research
unrestricted non-commercial use, provided the original work is properly cited

Open $\odot$ Access

Research Article

\title{
Spectrochemical Investigation of di methoxy Aniline Dithiocarbamate metal complexes-Biological activity
}

\author{
A. Somasekhar ${ }^{1 *}$, A. Jayaraju ${ }^{2}$, and J. Sreeramulu ${ }^{2}$ \\ ${ }^{1}$ Department of Chemistry, Sri Krishnadevaraya University, Anantapuramu-515003, India \\ ${ }^{2}$ Department of Chemistry, Dravidian University, Kuppam-517426, India
}

\begin{abstract}
Dithiocarbomates are a class of sulfur-based metal-chelating compounds commonly used in industry, agriculture, and medicine. 2,6 di methoxy Aniline dithiocarbamate Complexes of Copper and Ruthenium have been prepared and Characterized by Spectroscopic methods like IR,NMR and also analysis of Biological activity. The investigation of these complexes confirmed that the stability of metal-ligands coordination through, $\mathrm{S} \& \mathrm{~S}, \mathrm{~N}$ atoms as bidendate chelates.
\end{abstract}

Keywords: 2,6 di methoxy Aniline dithiocarbamate Metal Complexes, Copper Chloride, Ruthenium Chloride

Article Info: Received 11 Oct 2019; $\quad$ Review Completed 20 Nov 2019; $\quad$ Accepted 28 Nov 2019; Available online 15 Dec 2019

Cite this article as:

Somasekhar A, Jayaraju A, Sreeramulu J, Spectrochemical Investigation of di methoxy Aniline Dithiocarbamate metal complexes-Biological activity, Journal of Drug Delivery and Therapeutics. 2019; 9(6-s):88-92 http://dx.doi.org/10.22270/jddt.v9i6-s.3741

[D.

A. Soma Sekhar, Department of Chemistry, Sri Krishnadevaraya University, Anantapuramu-515003

\section{INTRODUCTION}

The field dithiocarbamate metal complexes are vast and fast developing on account of their spectacular applications in various fields, also owing to the varieties of structural forms of the ligands. The ever-increasing applications of transition metal complexes in different fields of sciences are the driving force for the present research. The dithiocarbamates are organo sulphur compounds considered to be versatile organic ligands which form complexes with many transition metals like $\mathrm{Cu}, \mathrm{Fe}, \mathrm{Ni}, \mathrm{Mn}$ and $\mathrm{Zn}$ leading to the stabilization of a wide range of oxidation states.

The complexing ability of dithiocarbamate is well established and this is due to two sulphur atoms, which are capable to donate a lone pair of electrons to the central metal atom to form the stable metal complexes. These are known to stabilize unusual oxidation states of metal complexes, because of the delocalization of positive charge from the metal to nitrogen. Besides, dithiocarbamate ligand and its metal complexes exhibit their striking and diversified applications in many fields like Medicine, Agriculture Industry, Polymer technology, Inorganic and Environmental trace analysis.

Dithiocarbamate ligands are soft bases. They had been found to act almost as uni negative bi dentate ligands coordinating through sulphur atoms, and also both tetra and hexa coISSN: 2250-1177 ordinate complex of many transitional metal ions have been isolated. They exhibit various applications in different fields especially in the production of petroleum derivatives, lubricants, as accelerators for vulcanization in Polymer Industry, as antioxidants and anti-humidity agents. They are also having fungicidal, bactericidal, insecticidal, anticancer, and photochemical activities. dithiocarbamate ligands itself acts as a good antibacterial and antifungal activity and are used as biocides (vapam, nabam).

Owing to wide applicability of sulphur bearing ligands in biological and industrial field, a bulk of literature is available on the dithiocarbamate ligands and its complexes of transition and non-transition metals. A large number of transition metal complexes with various aliphatic and aromatic dithiocarbamate ligands have been reported. Though a number of dithiocarbamates have been prepared in the literature, there is no attempt in preparation of DMADTC,

2,6 di methoxy Aniline is used as an antiasthamatics, dermatologistics disorders and also treating for wounds, burns, ulcer, scars, keloids.

The present work has been extended to know antibacterial activity, anti inflammatory activity and antifungal activity of dithiocarbamate metal complexes. 
The main thrust of the study is to prepare as such new dithiocarbamate ligand from an amine having considerable amount of applications on its own with the hope that the resultant dithiocarbamate may possess much more applications and find a place in major fields of interest.

\section{MATERIALS AND METHODS}

\section{Experimental Section}

Copper chloride anhydrous was obtained from Fluka, 2,6 di methoxy Aniline and carbon disulfide were purchased from Aldrich. Other chemicals used were of analytical reagent or higher purity grade. Solvents used were of reagent grade and purified before use by the standard methods. Conductivity measurement was carried out by a Systronics conductivity bridge 305, using a conductivity cell of cell constant 1.0 double distilled water was used as solvent. Electronic absorption spectra on JAS.CO UV/VIS-7850 recording spectrophotometer. Infrared spectra was recorded on a JAS.Co-460 plus FT-IR spectrophotometer in the range of $4000-400 \mathrm{~cm}^{-1}$ in $\mathrm{KBr}$ pellets. Micro chemical analysis of carbon, hydrogen and nitrogen for the complexes were carried out on a Herause CHNO-Rapid elemental analyzer. ${ }^{1} \mathrm{H}$ NMR spectra were recorded on a Brucker DRX-500 Advance spectrometer at $500 \mathrm{MHz}$ in DMSO-discussing tetra methyl silane as internal reference standard. Melting points were measured on a unimelt capillary melting Point apparatus and reported uncorrected.

\section{Synthesis of DMADTC}

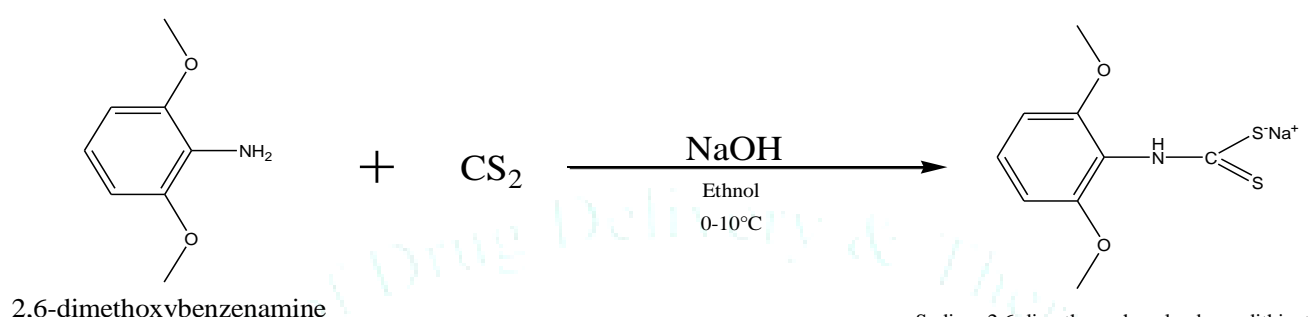

M.F: $\mathrm{C}_{8} \mathrm{H}_{11} \mathrm{NO}_{2}$

Sodium 2,6-dimethoxyphenylcarbamodithioate

Mol. Wt.: 153.18

\section{Synthesis of [M ((DMADTC) $\left.\left.)_{2}\right)\right]$ Complex}

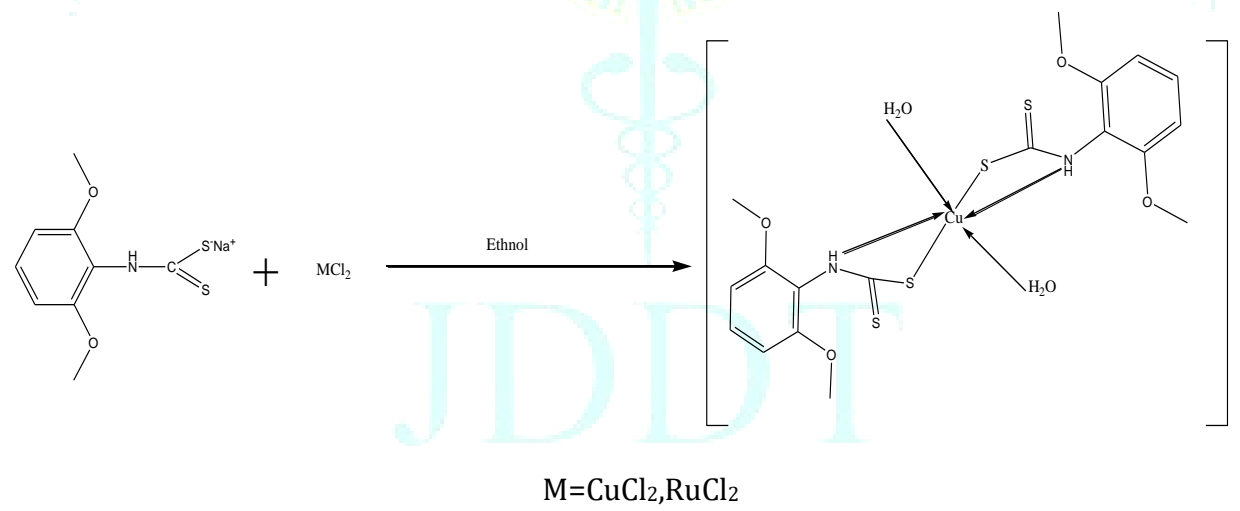

\section{Preparation of Sodium salt of 2,6 di methoxy Aniline dithiocarbamate ligand}

$0.05 \mathrm{~mol}$ of amine was dissolved in $30 \mathrm{ml}$ of absolute alcohol in a clean beaker which was placed in ice bath. To this cold solution add $5 \mathrm{ml}$ of Sodium hydroxide $(10 \mathrm{~N})$ solution, and then add Pure carbon disulphide $(0.05 \mathrm{ml})$ in drop wise with constant stirring. The contents were stirred mechanically for about $30 \mathrm{~min}$, sodium salt of dithiocarbamate precipitated out. It was dried over and recrystallized from ethanol.

\section{Preparation of $\mathrm{Cu}$ (II) and $\mathrm{Ru}$ (II) Complexes}

\section{Synthesis of [Cu ((DMADTC) $\left.)_{2}\right)_{\left.\mathrm{Cl}_{2}\right]}$}

The aqueous solution of $0.05 \mathrm{~mol}$ of Cupper Chloride was added with constant stirring to an aqueous solution of 0.01 mol of Sodium salt of 2,6 di methoxy Aniline dithiocarbamate ligand. The reaction mixture was stirred at room temperature for 2 hours. The colored (yellow) precipitates were obtained. The precipitates were filtered and washed with water and then with methanol and dried over calcium chloride in desiccator's Yield:78\% and decomposes at $110 \mathrm{C}$.

Anal. Calcd. C, 37.59; H, 4.27; Cu, 11.70; N, 5.16; 0, 17.67; S, 23.61

\section{Synthesis of [Ru (DMADTC)Cl $\left.\mathrm{Cl}_{2}\right]$}

The aqueous solution of $0.05 \mathrm{~mol}$ of Ruthenium Chloride was added with constant stirring to an aqueous solution of 0.01 mol of Sodium salt of 2,6 di methoxy Aniline dithiocarbamate ligand in the presence of small quantity of triethylamine. The reaction mixture was stirred at room temperature for 2 hours. The colored (gray) precipitates were obtained. The precipitates were filtered and washed with water and then with methanol and dried over calcium chloride in a desiccator Yield: $80 \%$ and decomposes at $110^{\circ}$ C. Anal. Calcd. For C, 36.41; H, 4.07; N, 4.72; 0, 16.17; $\mathrm{Ru}, 17.02 ; \mathrm{S}, 21.60$ 


\section{RESULTS AND DISCUSSION}

Solid reflectance spectra data for the $\mathrm{Cu}$ and $\mathrm{Ru}$ of $2,6 \mathrm{di}$ methoxy Aniline metal complexes. The complexes $\left[\mathrm{Cu}(\mathrm{DMADTC})_{2} \mathrm{Cl}_{2}\right]$ and $\left[\mathrm{Ru}(\mathrm{DMADTC})_{2} \mathrm{Cl}_{2}\right]$ complexes exhibit magnetic property and has an electronic spectrum which can be assigned to low spin $\mathrm{Cu}$ (II) and $\mathrm{Ru}$ (II) in an Octahedral Environment. Intra ligand electronic transition in then...C...S...S and S...C...S chronophers of the dithiocarbamate moiety. Thus the peak at $646 \mathrm{~nm}$ and the shoulder at $499 \mathrm{~nm}$ arise from 1A1g_1T1g and 1A1g_ 1T2g transitions, respectively. The other lower peaks are probably charge-transfer in origin.

\section{Infrared Spectrum}

Two regions of the IR spectrum of the [Cu(DMADTC $\left.)_{2}\right)_{2} \mathrm{Cl}_{2}$ ] and $\left[\mathrm{Ru}(\mathrm{DMADTC})_{2} \mathrm{Cl}_{2}\right]$ complex have proven valuable in arguments concerning the electronic and structural characteristics of this compound. The presence of the thiouride band between 1535-1452 $\mathrm{cm}^{-1}$ suggest a considerable double bond character in the C...N bond vibration of the $\mathrm{S}_{2} \mathrm{C}-\mathrm{NR}_{2}$ group. The band present in the 967 $\mathrm{cm}^{-1}$ range is attributed to the prevailing contribution of (C...S) Vibrations in these ranges have been used defectively in differentiating between monodentate, bidentate dithiocarbamates ligands. The presence of only one strong band supports bidentate coordination of the dithio ligands, where as a doublet is expected in the case of monodentate coordination. (C...S) and (C...N) Stretching frequencies fall in the $1105 \mathrm{~cm}^{-1}\left(1001 \mathrm{~cm}^{-1}\right.$ for the free ligand ) and $1478 \mathrm{~cm}^{-1}$ respectively. The methoxy group in the complex, as medium strong bands in the $2876 \mathrm{~cm}^{-1}$ range can be related to the asymmetric $\mathrm{CH}_{3}$ stretching vibration.

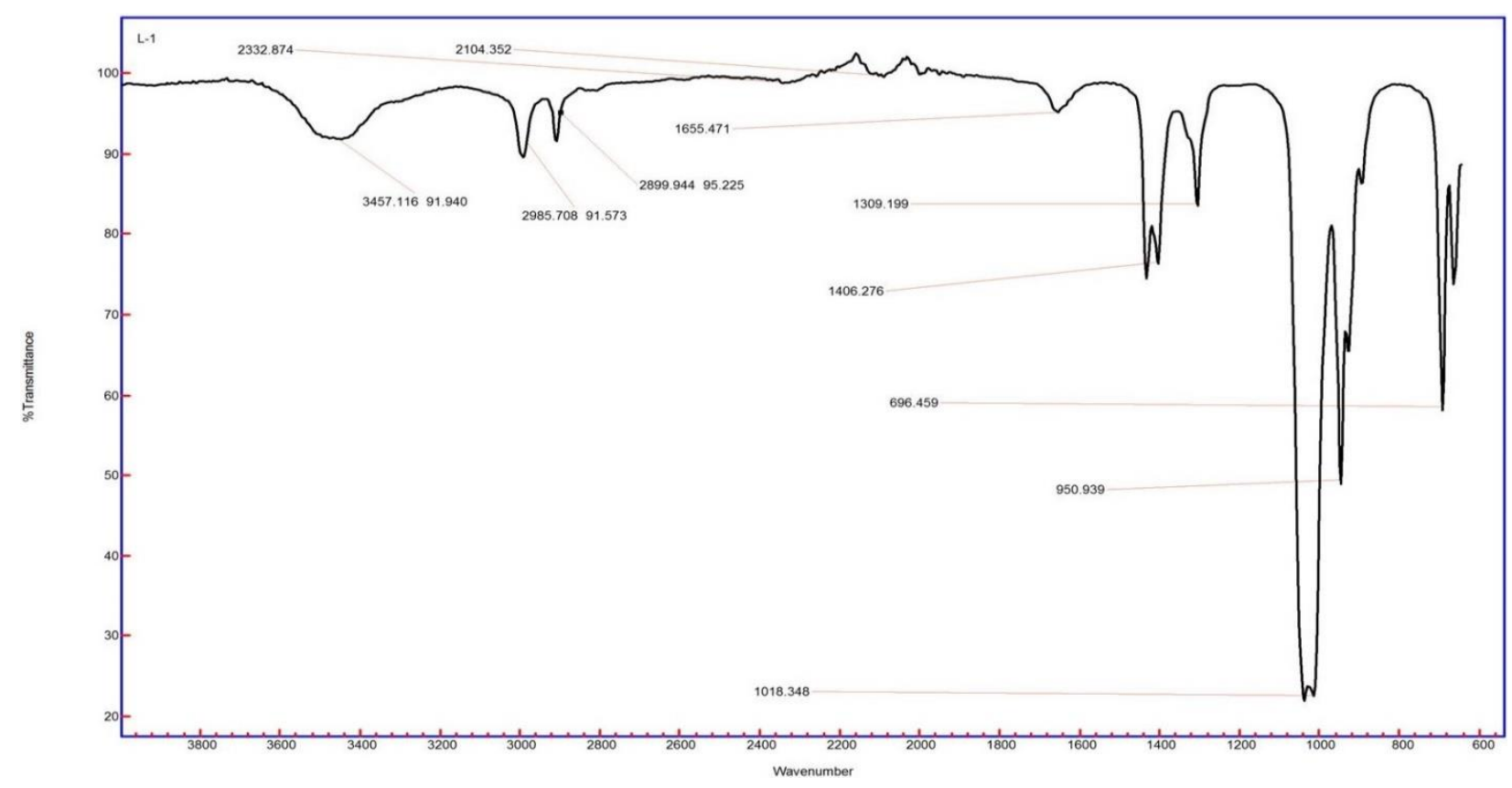

IR Spectrum of DMADTC Ligand

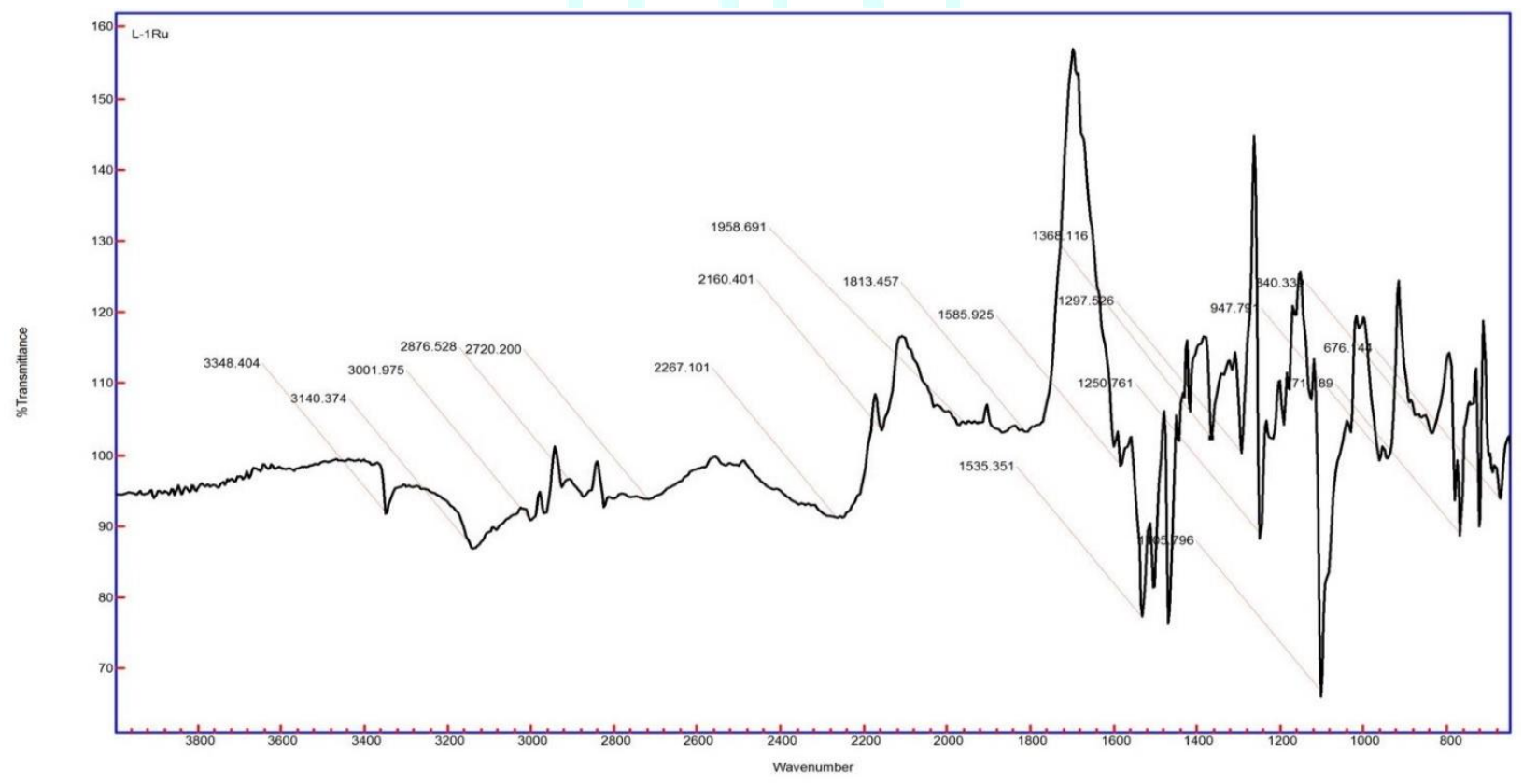

IR Spectrum of [Cu(DMADTC $\left.)_{2}\right)_{\left.C_{2}\right]}$ 


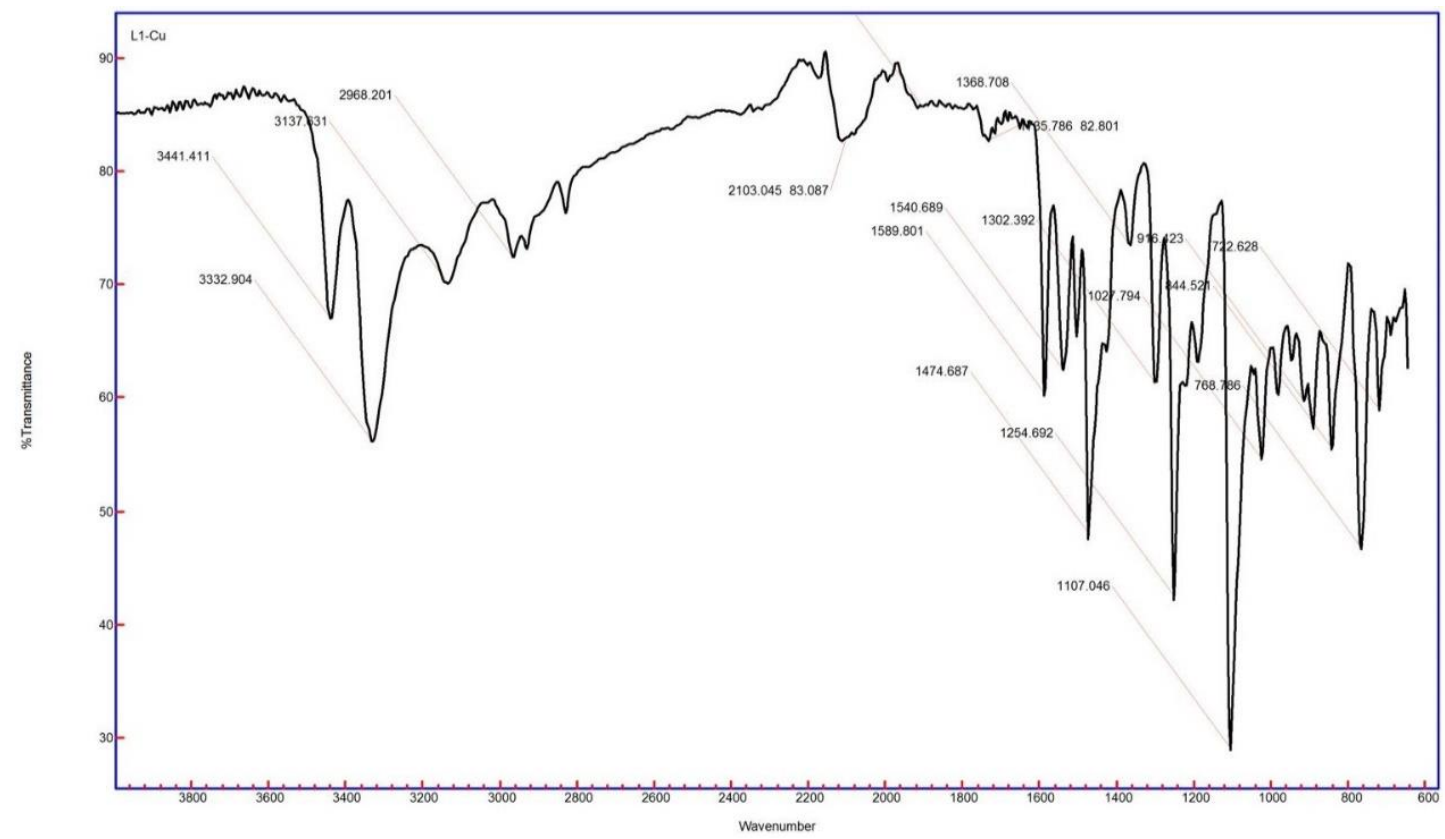

IR Spectrum of [Ru(DMADTC $\left.)_{2}\right)_{\left.C_{2}\right]}$

\section{H1-NMR Spectra}

The NMR spectrum of the [Cu(DMADTC) 2$)]$ and [Ru(DMADTC $)_{2}$ ] complexes showed at 3.7-3.8 ppm. Which may be assigned to the hydroxyl protons. The peak at 7.97.98 attributed to $\mathrm{NH}$ protons of thiouraide nitrogens in both complexes.

\section{Antimicrobial Activity}

Antimicrobial test was performed on four bacterias (Staphylococcus aureus, Bacillus subtilis, Escherichia coli, Pseudomonas aeruginosa,) and two fungi (Candida albicans and Candida tropicalis). The media used were prepared by dissolving separately $2 \mathrm{~g}$ of nutrient broth powder and $38 \mathrm{~g}$ of the Mueller-Hinton agar powder in $250 \mathrm{ml}$ and $1 \mathrm{~L}$ of deionized water, respectively. Two media were sterilized in an autoclave at $121^{\circ} \mathrm{C}$ for 15 minutes and then stored overnight in a refrigerator after cooling. Cultures of the microorganisms were prepared in sterile nutrient broth and incubated for 24 hours at $37^{\circ} \mathrm{C}$ for the bacteria and $27^{\circ} \mathrm{C}$ for the fungi. $0.1 \mathrm{ml}$ of each of the overnight cultures in sterile test tubes with caps were made up to $10 \mathrm{ml}$ with $9.9 \mathrm{ml}$ of sterile deionized water.

\begin{tabular}{|c|c|c|c|c|c|c|}
\hline \multicolumn{5}{|c|}{ Growth inhibition zone in millimetres(mm) } & \multirow{2}{*}{\multicolumn{2}{|c|}{ Fungus }} \\
\hline \multicolumn{5}{|c|}{ Bacteria } & & \\
\hline & \multicolumn{2}{|c|}{ Gram+Ve } & \multicolumn{2}{|c|}{ Gram -Ve } & & \\
\hline & S.aur & B.Subt & E.Coli & P.aerug & C.alb & C.trop \\
\hline [Cu(DMADTC)2)] & 14 & 14 & 15 & 14 & 14 & 15 \\
\hline [Ru(DMADTC)2)] & 13 & 15 & 14 & 14.5 & 16 & 14 \\
\hline FLU & & & $\begin{array}{ll}-\cdots--- \\
\end{array}$ & $+\cdots---$ & 15 & 15 \\
\hline DMSO & 12 & 14 & 15 & 16 & ----- & $\begin{array}{c}--- \\
\end{array}$ \\
\hline
\end{tabular}

To give 1:100 or 10-2 dilution of the microorganisms. The technique used for the study was agar-well diffusion. Solutions of concentration $10 \mathrm{mg} / \mathrm{ml}$ of the compounds were made in dimethyl sulphoxide (DMSO). DMSO was also used as the negative control. Positive controls for bacteria and fungi were discs of commercial antibiotics manufactured by Abtek Biological Limited and Fluconazole dissolved in DMSO. The discs were carefully placed on the inoculated media with the aid of sterile forceps. Plates inoculated with bacteria were incubated at $37^{\circ} \mathrm{C}$ for 24 hours, and those inoculated with fungi were incubated at $27^{\circ} \mathrm{C}$ for 72 hours. Afterwards, the zones of inhibition of microbial growth that appeared around the wells of the compounds were examined and the diameters measured and recorded in millimeters $(\mathrm{mm})$. Antimicrobial activity of the $\mathrm{Cu}$ (II) and $\mathrm{Ru}$ (II) complexes was evaluated in vitro against Gram positive bacteriaStaphylococcus aureus and Bacillus subtilis, Gram negative bacteria- Escherichia coli, Pseudomonas aeruginosa and fungi, Candida albicans, Candida tropicalis. The results for the complexes and commercial antibiotics used as positive controls are listed in (Table 1). 


\section{CONCLUSION:}

$\mathrm{Cu}$ (II) and $\mathrm{Ru}(\mathrm{II})$ complexes of 2,6 di methoxy Aniline dithiocarbamate Ligand with have been synthesized and characterized. The ligand moiety exhibit a bidentate coordination mode in the $\mathrm{Cu}$ (II) and Ru (II) complexes. Solid reflectance spectra and magnetic data indicate that the complexes are Paramagnetic and Octahedral. The complexes show selective activity towards some of the test microorganisms.

\section{ACKNOWLEDGEMENT}

The great thankful to the Department of Chemistry, Sri Krishnadevaraya University, Anantapur, India is acknowledged for the microanalysis, infrared spectra and thermo gravimetric analysis, conductivity and magnetic susceptibility measurements of the compounds.

\section{REFERENCES}

[1]. AAM Aly; MM Kamal; MS El-Meligy; ASA Zidan; M El-Shabasy. Synth. React. Inorg. Met.-Org. Chem., 1987, 17(3), 237-274.

[2]. AAM Aly; MS El-Meligy; ASA Zidan. Transition Met. Chem., 1989, 14, 366-368.

[3]. AI El-Said; AAM Aly. Synth. React. Inorg. Met.-Org. Chem., 1990, 1059-1069.

[4]. PA Ajibade; GA Kolawole. J. Coord. Chem., 2008, 61(21), 33673374.

[5]. A Hulanicki. Talanta, 1967, 14, 1371-1392.

[6]. D Coucouvanis. Prog. Inorg. Chem., 1970, 11, 233-371.

[7]. G Manoussakis; C Bolos; L Ecateriniadou; C Sarris. Eur. J. Med. Chem., 1987, 22, 421-425.

[8] .L Giovagnini; C Marzano; F Bettio; D Fregona. J. Inorg. Biochem., 2005, 99, 2139-2150.

[9]. A Manohar; K Ramalingam; R Thiruneelakandan; G Bocelli; L Righi. Z. Anorg. Allgem. Chem., 2006, 632, 461-464.

[10]. R Pastorek; J Kameníček; J Husárek; V Slovák; M Pavlíček. J. Coord. Chem., 2007, 60(5), 485-494. 